\title{
Technical Documents Used in Dose Reconstruction
}

\section{Q: When does NIOSH use technical documents in dose reconstruction?}

A: If the energy employee's personal radiation information is incomplete, $\mathrm{NIOSH}$ will use other sources to estimate the radiation dose. This may involve using technical documents called Site Profiles, Technical Basis Documents, and Technical Information Bulletins.

\section{Q: What are Site Profiles?}

A: Site Profiles are documents that describe a specific work site. A Site Profile includes the physical appearance and layout of the site, the work processes used there, the types of materials used, potential sources of radiation, and other details important at that site.

\section{Q: What are Technical Basis Documents?}

A: Technical Basis Documents (also called TBDs) are the individual documents that form a Site Profile. An individual TBD contains information on a specific aspect of the site. This aspect may be the physical layout of the site, the work processes used, or other particular features of the site and the work performed there.

\section{Q: What are Technical Information Bulletins?}

A: Technical Information Bulletins (also called TIBs) contain information on specific technical issues or procedures for estimating radiation exposure. They are used to add to or supplement TBDs and Site Profiles. TIBs may be used for a specific site or multiple sites. 
For more information on technical documents

or to see example documents, visit www.cdc.gov/niosh/ocas

E-mail questions to: dcas@cdc.gov or call 1-877-222-7570

DHHS (NIOSH) Publication No. 2005-140

Department of Health and Human Services

Centers for Disease Control and Prevention National Institute for Occupational Safety and Health 